\title{
Diosmetin Inhibits Cell Proliferation, Induces Cell Apoptosis and Cell Cycle Arrest in Liver Cancer
}

This article was published in the following Dove Press journal:

Cancer Management and Research

\author{
Aiqing $\mathrm{Ma}^{\mathrm{I}}$ \\ Rui Zhang (iD) ${ }^{2}$ \\ 'Department of Operating Room, Linyi \\ Cancer Hospital, Linyi, Shandong, \\ People's Republic of China; ${ }^{2}$ Department \\ of Thoracic Surgery, Linyi Cancer \\ Hospital, Linyi, Shandong, People's \\ Republic of China
}

Objective: Diosmetin (DIOS) has been confirmed to possess anti-cancer effects in some types of tumors. However, it remains unclear whether DIOS exerts anti-cancer effects on liver cancer. Thus, our purpose was to observe the effect of DIOS on cell proliferation, cell apoptosis and cell cycle arrest in human liver cancer cells.

Materials and Methods: The cell viability of HepG2 and HCC-LM3 cells under different concentrations of DIOS was detected using MTT assay. The cell apoptosis and cell cycle arrest were analyzed by flow cytometry. The expression levels of apoptosis/cell cycle-related proteins including P53, Bcl-2, Bax, cleaved-caspase3, cleaved-caspase8, cleaved-PARP, Bak, cdc2, cyclinB1 and P21 were measured using Western blot. HepG2 cells were transfected by checkpoint kinase 1 (Chk1)-small interfering RNA (siRNA) and checkpoint kinase 2 (Chk2)siRNA, respectively. After that, cell cycle was detected.

Results: DIOS significantly suppressed cell proliferation and induced cell apoptosis of HepG2 cells and HCC-LM3 cells. Moreover, DIOS promoted cell cycle arrest in G2/M phase. Western blot results showed that DIOS significantly suppressed the expression levels of Bcl-2, cdc2, cyclinB1, and promoted the expression levels of Bax, cleaved-caspase3, cleaved-caspase8, cleaved-PARP, Bak, P53, and P21. The G2/M phase arrest was observed in HepG2 cells transfected with Chk2-siRNA, while the G2/M phase arrest was not obvious in HepG2 cells transfected with Chk1-siRNA.

Conclusion: Our findings revealed that DIOS could inhibit cell proliferation and promote cell apoptosis and cell cycle arrest in liver cancer. Furthermore, DIOS could induce G2/M cell cycle arrest in HepG2 cell via targeting Chk2.

Keywords: diosmetin, cell apoptosis, cell cycle arrest, liver cancer, HepG2 cell

\section{Introduction}

Liver cancer is one of the most common malignant tumors worldwide. ${ }^{1-3}$ The number of patients who die of liver cancer worldwide is as high as 16 million per year. ${ }^{4}$ China is a high-risk area of primary liver cancer in the world. ${ }^{5}$ The occurrence and development of liver cancer is closely related to hepatitis B virus infection, long-term alcohol abuse, bad eating habits, and mildew food intake. ${ }^{6}$ At present, the number of liver cancer patients in China accounts for about half of the total number of liver cancers in the world. ${ }^{7}$ Liver cancer has become a malignant disease that seriously threatens people's health and life. The chemotherapy drugs for postoperative liver cancer have improved the treatment of liver cancer patients and improved their survival time. ${ }^{8}$ The significance of the expected treatment is better when using these drugs for postoperative chemotherapy, but the main problem is that these chemotherapeutic drugs have a large cytotoxic effect, and
Correspondence: Rui Zhang

Department of Thoracic Surgery, Linyi

Cancer Hospital, Linyi, Shandong 27600I,

People's Republic of China

Email Zhangruidoctor123@163.com 
the selectivity to tissue receptors is poor. ${ }^{9}$ In recent years, targeted therapy of drugs has attracted attention due to specific receptor proteins and small side effects on normal cells. $^{1,10,11}$ Although the occurrence and development of tumors is an extremely complicated process of genetic alteration, most tumors are accompanied by a process of genetic mutations. ${ }^{12}$ Even for the same type of tumor, malignant cell clusters are caused by changes in different genes leading to the formation of heterogeneous cells. Moreover, along with the misconfiguration of tumors, the mutated genes in tumor cells are constantly changing. So it is extremely difficult to inhibit the proliferation of tumor cells by targeting drugs targeting single gene. ${ }^{13}$ Therefore, through the use of the differences between the biological metabolism of tumor cells and normal cells, further exploration of targeted specific anti-tumor drugs is a new strategy for the development of anti-tumor drugs.

In the field of drug development in the new era, natural product can enhance the anti-tumor effect of natural Chinese herbal medicine by improving the purity, efficiency and targeting of tumor receptors. These natural products include some semi-synthetic taxane derivatives and flavonoids. ${ }^{14,15}$ Related studies have shown that most flavonoids have anti-tumor characteristics against multiple genes, multiple sites, and multiple pathways, and they also have low toxicity. ${ }^{16,17}$ The pharmacological effects of flavonoids in anti-tumor, cell cycle arrest and cell apoptosis have been widely recognized. ${ }^{18,19}$ DIOS is a flavonoid compound found mainly in the peels of oranges and lemons. It has anti-oxidant, anti-tumor and anti-mutagenic properties. Studies have found the anti-tumor effects of DIOS on inhibiting tumor cell proliferation. ${ }^{20}$ However, the mechanism of anti-tumor activity of DIOS in liver cancer is poorly understood. In this study, we aimed to investigate the effects of DIOS on the cell viability, apoptosis and cell cycle arrest in human hepatoma HepG2 cells and HCC-LM3 cells.

\section{Materials and Methods}

\section{Reagents}

DIOS was purchased from Sigma (USA). AnnexinV-FITC/PI Apoptosis Assay Kit was purchased from BD (USA). Human p53, Bcl-2, Bax, cleaved-caspase3, cleaved-caspase8, cleaved-PARP, Bak, cdc2, cyclinB1 and p21 antibodies were purchased from CST (USA). Octamethylazozolium blue (MTT) and propidium iodide (PI) stains were purchased from Sigma. Cell protein extraction kit was purchased from Biyuntian (China).

\section{Cell Culture}

The human hepatoma cell lines including HepG2 and HCC-LM3 and human normal liver cell line LO2 were purchased from the Shanghai Cell Bank (China, Shanghai). The cells were cultured in RPMI-1640 medium (Gibco, Thermo Fisher Scientific, Inc., USA) containing $10 \%$ fetal bovine serum (FBS; Gibco, Thermo Fisher Scientific, Inc., USA), $100 \mathrm{U} / \mathrm{mL}$ penicillin, $100 \mathrm{mg} / \mathrm{L}$ streptomycin in $37^{\circ} \mathrm{C}$ incubator with $5 \% \mathrm{CO}_{2}$. The cells were passaged for 2 to 3 days, and the cells in the logarithmic growth phase were taken for further experiments.

\section{MTT Assay}

HepG2, HCC-LM3 and LO2 cells in the logarithmic growth phase were digested, counted, and mixed with $10 \%$ FBS to prepare $7.5 \times 10^{3}$ cells/well for inoculation in 96-well culture plates for $24 \mathrm{~h}$. After the cells were attached, different concentrations of DIOS were added (final drug concentrations were $0,1,2,5,10,15,20,25$, $30 \mu \mathrm{g} / \mathrm{mL}$ ). The cells were cultured for $6 \mathrm{~h}, 12 \mathrm{~h}, 24 \mathrm{~h}, 48$ $\mathrm{h}$, respectively. After that, the supernatant was discarded. One hundred $\mu \mathrm{L}$ DMSO was added to each well. After the crystals were sufficiently dissolved, the absorbance per well (A) was measured at a wavelength of $490 \mathrm{~nm}$. The cell proliferation inhibition rate was calculated as follows: Inhibition rate $=($ control group $\mathrm{A}-$ test group $\mathrm{A}) /($ control group A - blank group A) $\times 100 \%$.

\section{AnnexinV-FITC/PI Apoptosis Assay}

Flow cytometry was used to detect cell apoptosis. Briefly, HepG2 and HCC-LM3 cells were treated with different concentrations of DIOS for $24 \mathrm{~h}$, and the cell suspension was prepared. The cells were centrifuged for $5 \mathrm{~min}$ in pre-cooled phosphate buffer (PBS) to wash the cells. One hundred $\mu \mathrm{L}$ of the cell suspension was incubated with 5 $\mu \mathrm{L}$ of AnnexinV-FITC and PI in the dark for $20 \mathrm{~min}$. Four hundred $\mu \mathrm{L}$ of buffer was added before operating the machine to measure the apoptosis rate by flow cytometry.

\section{Cell Cycle Assay}

HepG cells in logarithmic growth phase (concentration of $4.5 \times 10^{3}$ cells $/ \mathrm{mL}$ ) were treated with DISO (final concentrations of $0,5,10,20 \mu \mathrm{g} / \mathrm{mL})$. The cells were collected after $24 \mathrm{~h}$, centrifuged at $1000 \mathrm{r} / \mathrm{min}$ for $5 \mathrm{~min}$, washed 
with pre-cooled PBS and then treated with $70 \%$ ethanol. After overnight fixation, the ethanol was removed by centrifugation, washed with pre-cooled PBS, stained with PI at $4^{\circ} \mathrm{C}$ for $30 \mathrm{~min}$ in the dark. The distribution of the cell cycle phase was detected by flow cytometry. The experiments were repeated at least three times independently.

\section{Western Blot Assay}

To detect the protein expression of cyclin p21, cdc2, cyclinB1, Bcl-2, Bax, cleaved-caspase3, cleavedcaspase8, cleaved-PARP and Bak protein, the HepG2 cells in logarithmic growth phase were collected and the total protein was extracted according to cellular protein extraction reagent. The protein content was determined by BCA method. The protein was denatured at $95^{\circ} \mathrm{C}$ for 10 $\mathrm{min}$, and $20 \mu \mathrm{g}$ protein sample was loaded on polyacrylamide gel for electrophoresis. Then, the protein separated from the gel was transferred onto the PVDF membrane. After 5\% skim milk was blocked for $2 \mathrm{~h}$, the primary antibodies were incubated at $4{ }^{\circ} \mathrm{C}$ for $24 \mathrm{~h}$, and the secondary antibodies were incubated at room temperature for $1 \mathrm{~h}$. After washing with TBST solution, the expression of the target bands was detected by chemiluminescence kit (GE Healthcare Life Sciences, Chalfont, UK).

\section{Cell Transfection}

Chk1-siRNA, Chk2-siRNA, Bcl-2-siRNA, cleavedcaspase8-siRNA, and their negative control (NC) were synthesized and purchased from Ribobio (Guangzhou, China). Transfection was performed using Lipofectamine 2000 (Invitrogen), according to the manufacturer's protocol.

\section{Statistical Analysis}

Statistical analyses were performed using SPSS 22.0 software (SPSS, Inc., Chicago, IL, USA) and Graphpad Prism 7.0 (San Diego, CA, USA). Data were expressed as mean \pm standard deviation (SD). All experiments were repeated at least three times. Comparisons were evaluated using student's $t$ test or one-way analysis of variance. $\mathrm{P}<0.05$ was considered statistically significant.

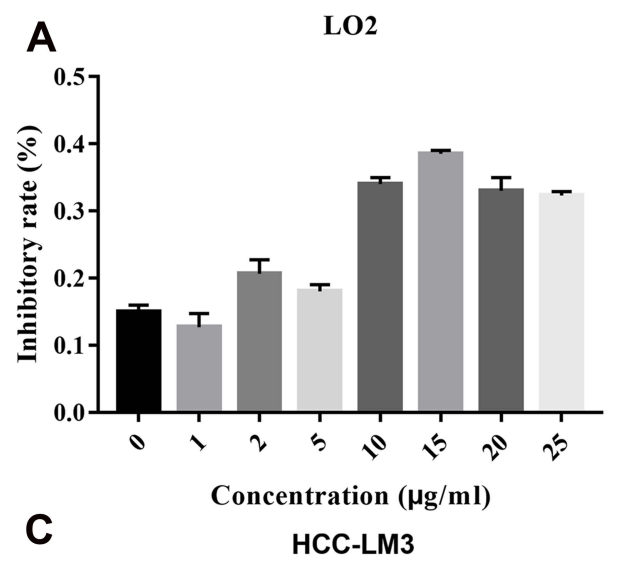

B

HepG2

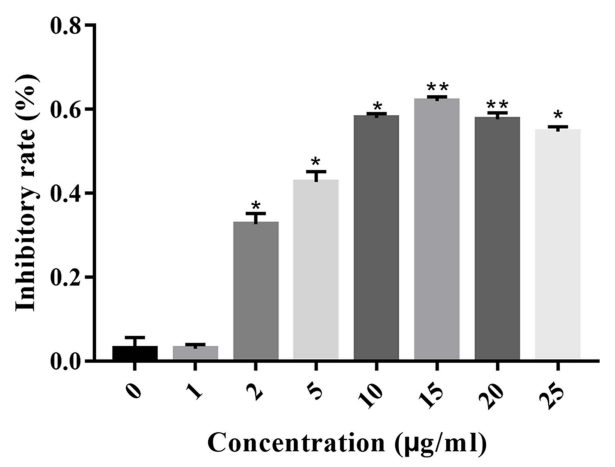

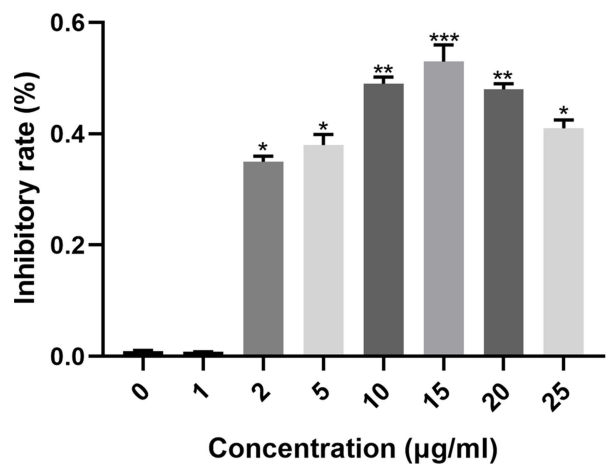

Figure I DIOS inhibits the cell viability of liver cancer cells using MTT assay. (A) The normal hepatocyte LO2 cells and liver cancer HepG2 (B) and HCC-LM3 (C) cells were treated with different concentrations of DIOS, respectively. The MTT assay was used to detect the cell viability. $* \mathrm{P}<0.05, * * \mathrm{P}<0.0 \mathrm{I}$ and $* * * \mathrm{P}<0.00 \mathrm{I}$.

Abbreviations: DIOS, diosmetin; MTT, 3-(4,5-dimethylthiazol-2-yl)-2,5-diphenyltetrazolium bromide. 


\section{Results}

\section{DIOS Inhibits the Cell Viability of Liver Cancer Cells}

The normal hepatocyte cell line LO2 and liver cancer cell line HepG2 and HCC-LM3 cells were treated with different concentrations of DIOS, respectively. MTT assay results showed that the cell viability of $\mathrm{LO} 2$ cells was not significantly inhibited under different concentrations of DIOS (Figure 1A). In contrast, we found that DIOS significantly suppressed the cell viability of HepG2 and HCC-LM3 cells, with a concentration-dependent manner (Figure 1B and C). Similarly, the results of the clone formation experiments showed that different concentrations of DIOS could not affect the proliferation of LO2 cells (Figure 2A and B). However, we found that DIOS significantly inhibited the proliferation of HepG2 and HCC-LM3 cells, with a concentration-dependent manner (Figure 2C-F). HepG2 cells were treated with different
A

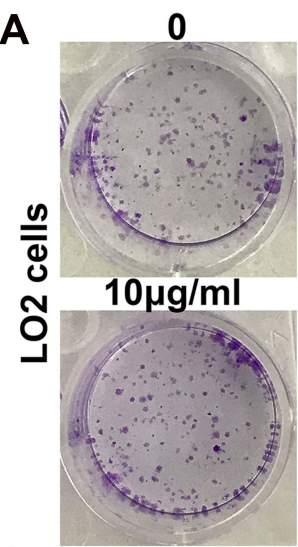

C

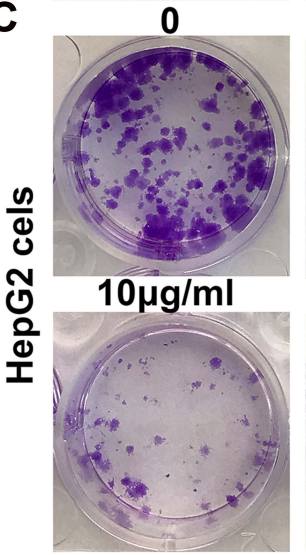

E

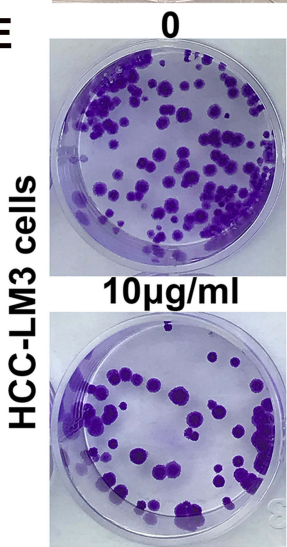

$1 \mu \mathrm{g} / \mathrm{ml}$
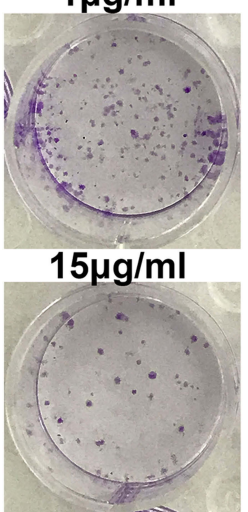

$1 \mu \mathrm{g} / \mathrm{ml}$

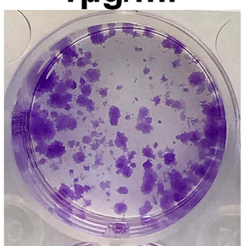

$15 \mu \mathrm{g} / \mathrm{ml}$

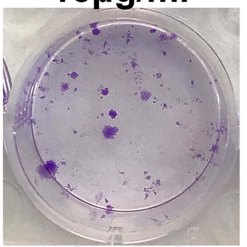

$1 \mu \mathrm{g} / \mathrm{ml}$

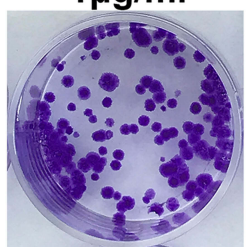

$15 \mu \mathrm{g} / \mathrm{ml}$

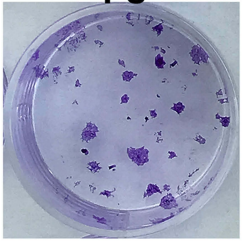

$2 \mu \mathrm{g} / \mathrm{ml}$
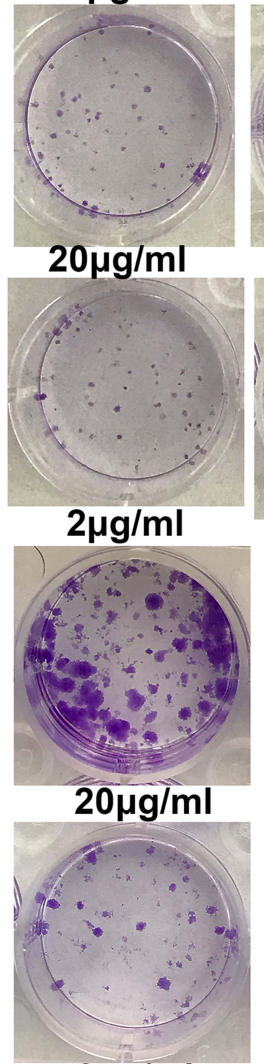

$2 \mu \mathrm{g} / \mathrm{ml}$

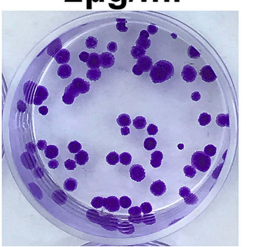

$20 \mu \mathrm{g} / \mathrm{ml}$

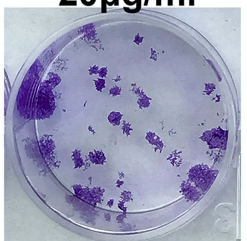

$5 \mu \mathrm{g} / \mathrm{ml}$

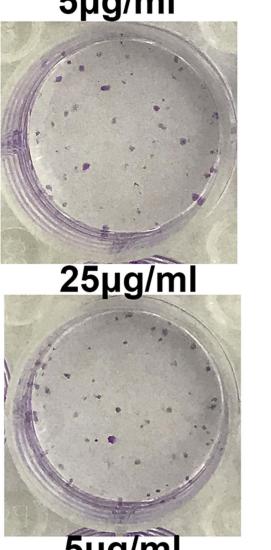

$5 \mu \mathrm{g} / \mathrm{ml}$

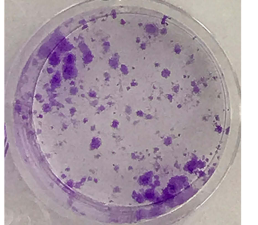

\section{$25 \mu \mathrm{g} / \mathrm{ml}$}

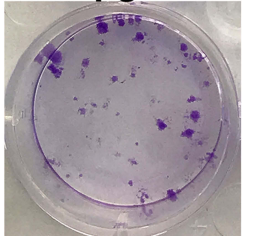

$5 \mu \mathrm{g} / \mathrm{ml}$

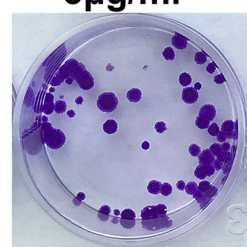

$25 \mu \mathrm{g} / \mathrm{ml}$

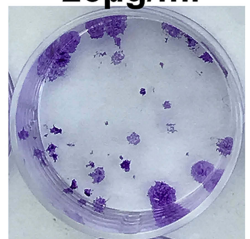

B

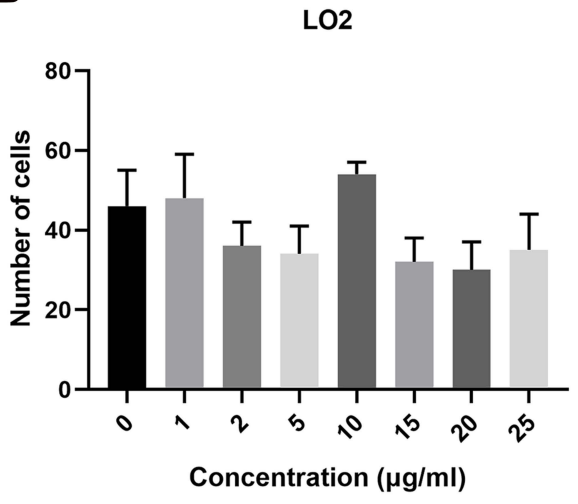

D

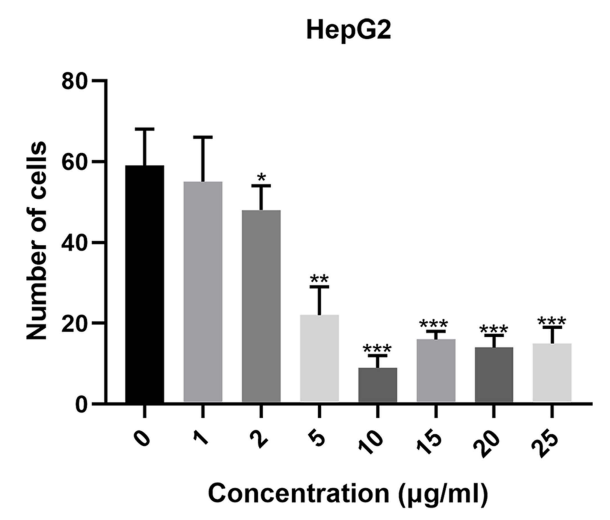

$\mathbf{F}$

HCC-LM3

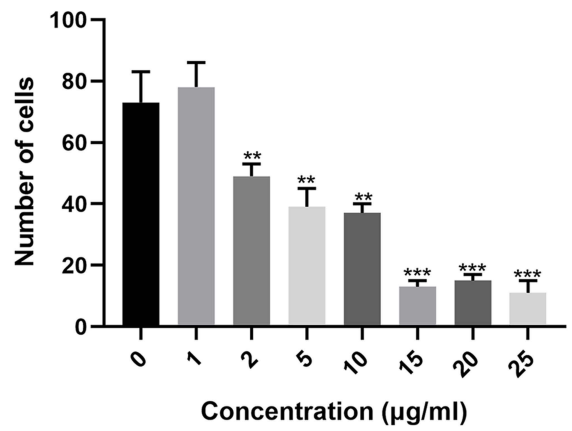

Figure 2 Clone formation assay results showing the inhibitory effects of different concentrations of DIOS on the proliferation of LO2 cells (A, B), HepG2 (C, D) and HCCLM3 cells $(\mathbf{E}, \mathbf{F})$. $* \mathrm{P}<0.05$, $* * \mathrm{P}<0.01$ and $* * * \mathrm{P}<0.001$.

Abbreviation: DIOS, diosmetin. 
A

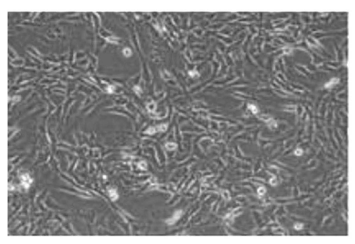

$0 \mu \mathrm{g} / \mathrm{ml}$

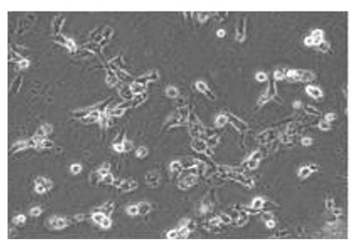

$10 \mu \mathrm{g} / \mathrm{ml}$

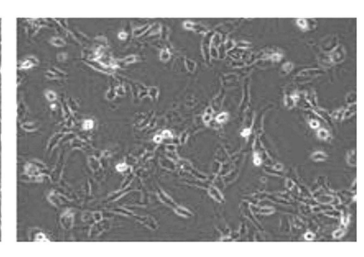

$5 \mu \mathrm{g} / \mathrm{ml}$

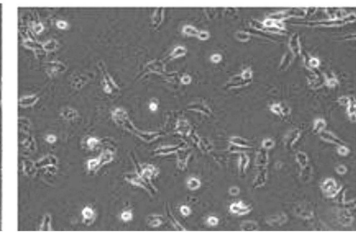

$15 \mu \mathrm{g} / \mathrm{ml}$
B

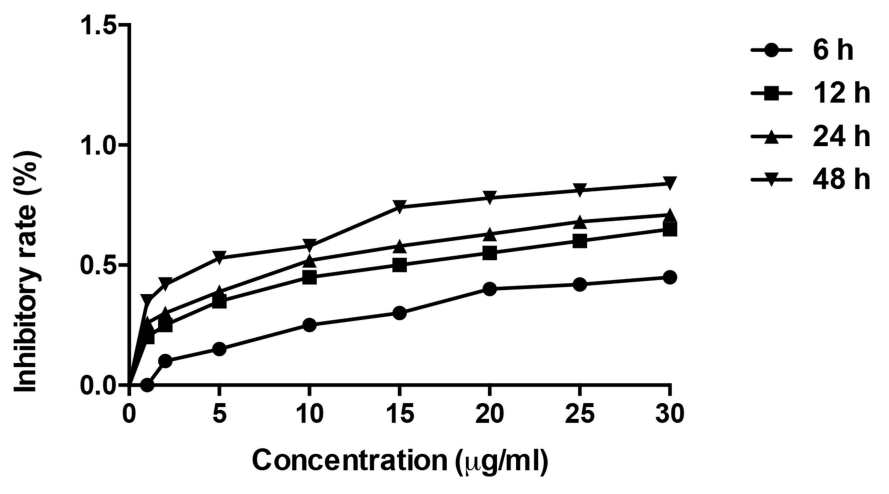

Figure 3 The cell morphology of HepG2 cells treated with DIOS. (A) HepG2 cells were treated with different concentrations $(0,5,10,15 \mu g / m L)$ of DIOS for $24 \mathrm{~h}$, and the cell morphology was observed under light microscopy. (B) MTT assay was used to detect the effect of different concentrations of DIOS on cell viability at different times (6, 12, 24, $48 \mathrm{~h})$.

Abbreviations: DIOS, diosmetin; MTT, 3-(4,5-dimethylthiazol-2-yl)-2,5-diphenyltetrazolium bromide.

concentrations $(0,5,10,15 \mu \mathrm{g} / \mathrm{mL})$ of DIOS for $24 \mathrm{~h}$. Under the microscope, we found that the cells in the control group were slender, vigorously growing, regular in morphology, clear in cell contour, and large in size (Figure 3A). However, as for the HepG2 and HCC-LM3 cells treated with DIOS, the cells were irregular in shape, the cell morphology became round, the cell gap increased, some cells were floating, and the cell debris increased with the increase of concentrations (Figure 3A). Moreover, DIOS significantly decreased the cells viability of HepG2 and HCC-LM3 cells with concentration-dependent and time-dependent manners (Figure 3B).

\section{DIOS Promotes Cell Cycle Arrest in G2/ $M$ and Cell Apoptosis of HepG2 Cells}

HepG2 cells were treated with different concentrations $(0,5,10,15 \mu \mathrm{g} / \mathrm{mL})$ for $24 \mathrm{~h}$, and flow cytometry was employed to analyze the cell cycle change. As shown in Figure 4A and C, the cells were blocked in G2/M phase. Furthermore, DIOS promoted the proportion of $\mathrm{G} 2 / \mathrm{M}$ phase, with a concentration-dependent manner. We also examined the cells apoptosis of HepG2 cells under different concentrations of DIOS. The results showed that DIOS significantly promoted cell apoptosis of HepG2 cells, with a concentration-dependent manner (Figure 4B and D). These results suggested that DIOS could induce cell cycle arrest in $\mathrm{G} 2 / \mathrm{M}$ and cell apoptosis of HepG2 cells.

\section{DIOS Is Involved in Regulating the Expression of Cell Cycle/ Apoptosis-Associated Proteins in HepG2 Cells}

After HepG2 cells treated with different concentrations of $\operatorname{DIOS}(0,5,10,15 \mu \mathrm{g} / \mathrm{mL})$ for $24 \mathrm{~h}$, we examined the expression levels of cell cycle/apoptosis-associated proteins in HepG2 cells using Western blot. The results showed that DIOS significantly inhibited the expression levels of cell cyclerelated proteins including cyclin B1 and cdc2, apoptosisrelated proteins including $\mathrm{Bcl}-2$ and cleaved-caspase 8 in HepG2 cells, with a concentration-dependent manner (Figure 5A). Furthermore, DIOS significantly promoted the expression levels of P53, P21, cleaved-PARP, cleavedcaspase3, Bax, Bak, P-Chk1, P-cdc25c, P-Chk2 and P-cdk1 in HepG2 cells, with a concentration-dependent manner (Figure 5B).

\section{DIOS Might Promote G2/M Arrest via Chk2 but Not Chkl in HepG2 Cells}

To further explore the mechanism by which DIOS might mediate $\mathrm{G} 2 / \mathrm{M}$ cell cycle arrest, we knocked down the expression of Chk1 and Chk2 by the corresponding siRNAs in HepG2 cells, respectively (Figure 6A). We found that DIOS significantly promoted the proportion of G2/M phase in HepG2 cells. After inhibiting Chk2, the proportion of $\mathrm{G} 2 / \mathrm{M}$ phase was significantly inhibited (Figure 6B). However, after inhibiting Chk1, the proportion 
A
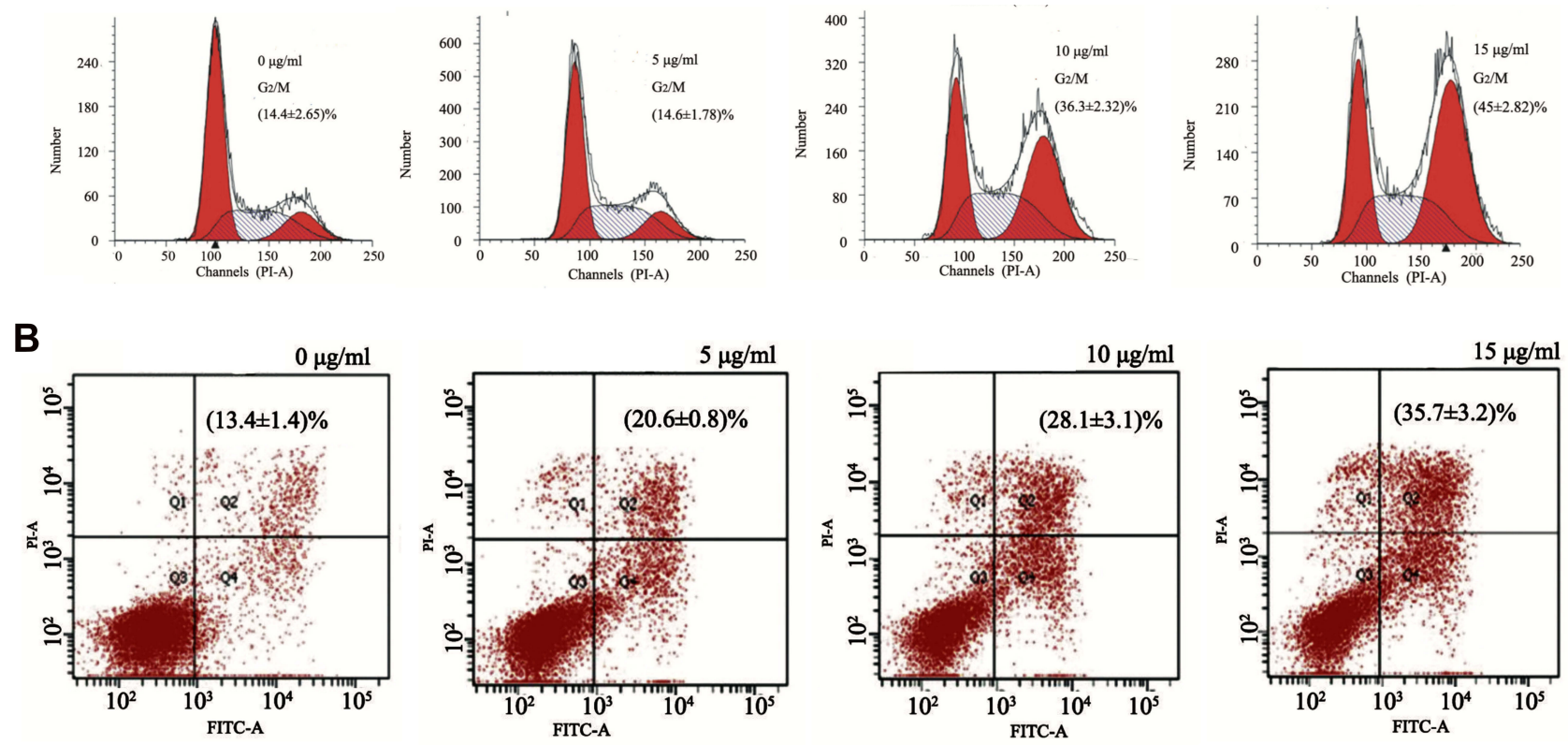

C

D
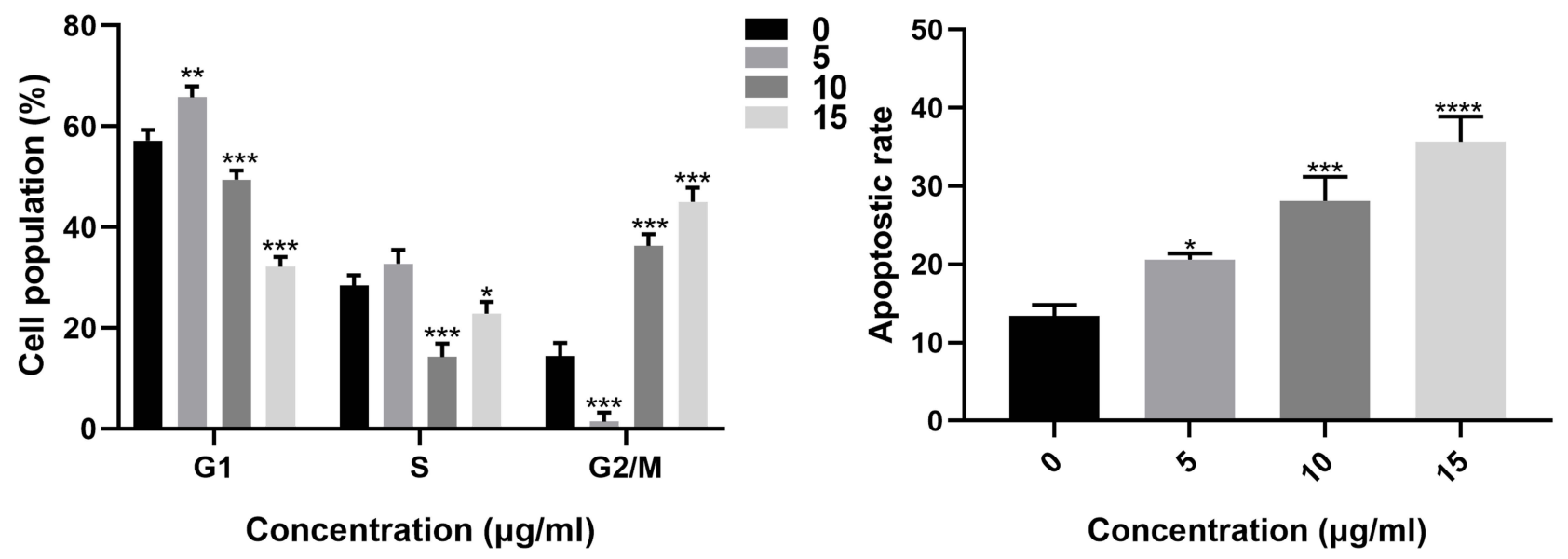

Figure 4 DIOS promotes cell cycle arrest in G2/M and cell apoptosis of HepG2 cells. (A, C) Flow cytometry was used to detect the cell cycle of HepG2 cells treated with different concentrations of DIOS $(0,5,10,15 \mu \mathrm{g} / \mathrm{mL})$ for $24 \mathrm{~h}$. (B, D) The apoptosis rate of HepG 2 cells under different concentrations of DIOS $(0,5$, I0, $15 \mu \mathrm{g} / \mathrm{mL})$ for 24 $\mathrm{h}$ was detected using flow cytometry. $* \mathrm{P}<0.05$, **P $<0.01$, *** $\mathrm{P}<0.001$ and $* * * * \mathrm{P}<0.000 \mathrm{I}$.

Abbreviations: PI-A, propidium iodide-area; GI, postsynthetic gapl period; S, DNA synthesis phase; G2, postsynthetic gap2 period; M, mitotic phase; FITC-A, fluorescein isothiocyanate-area; DIOS, diosmetin.

of $\mathrm{G} 2 / \mathrm{M}$ phase was not significantly inhibited (Figure 6B). DIOS might promote $\mathrm{G} 2 / \mathrm{M}$ arrest via Chk2 but not Chk1 in HepG2 cells.

\section{DIOS Might Promote HepG2 Cell} Apoptosis by $\mathrm{Bcl}-2$ and Cleaved-Caspase 8 We observed whether DIOS might promote HepG2 cell apoptosis by apoptosis-related proteins including Bcl-2 and cleaved-caspase8. As shown in Figure 7A and B, Bcl-2 and cleaved-caspase 8 were successfully silenced in HepG2 cells, respectively. Flow cytometry results suggested that DIOS significantly promoted HepG2 cell apoptosis. After inhibiting Bcl-2 or cleaved-caspase8, the inhibitory effects induced by DIOS were significantly reversed (Figure 7C). Thus, DIOS might promote HepG2 cell apoptosis by Bcl-2 and cleaved-caspase8.

\section{Discussion}

Liver cancer is a highly malignant and highly invasive solid tumor. ${ }^{21,22}$ At present, there is no effective treatment. 


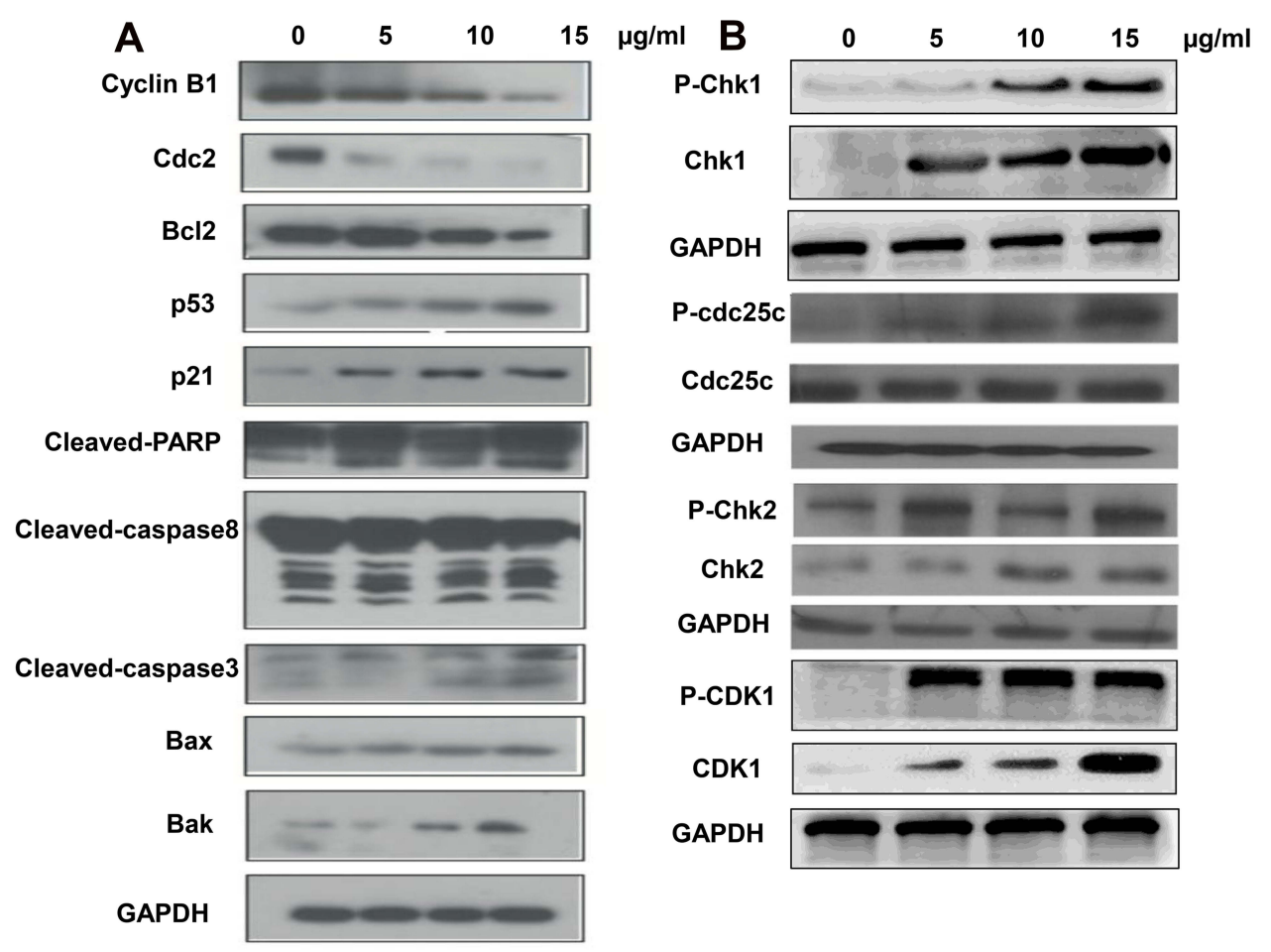

Figure 5 DIOS is involved in regulating the expression of cell cycle/apoptosis-associated proteins in HepG2 cells. HepG2 cells were treated with different concentrations of $\operatorname{DIOS}(0,5,10,15 \mu \mathrm{g} / \mathrm{mL})$ for $24 \mathrm{~h}$, and the expression levels of cell cycle/apoptosis-associated proteins were detected by Western blot (A, B).

Abbreviations: Cdc, cell division cycle 2, Bcl, B-cell lymphoma; PARP, poly ADP-ribose polymerase; Bax, BCL2-associated X; Bak, BCL2-Associated kinase; GAPDH, glyceraldehyde-3-phosphate dehydrogenase; Chk, cyclin-dependent kinase; DIOS, diosmetin.

DIOS as a flavonoid anticancer drug provides a new idea for the current anticancer treatment. ${ }^{23-25}$ In this study, we explored the anti-tumor mechanism of DIOS in human hepatoma HepG2 cells and HCC-LM3 cells.

We found that DIOS promoted G2/M phase arrest in HepG2 cells, while normal human liver cell LO2 had no significant changes after treatment with DIOS. It is well known that inhibition of the hepatoma cell cycle can induce the repression of liver cancer cell proliferation. The combination of cyclin and cyclin-dependent kinase (CDK) is closely related to cell cycle transition. ${ }^{26}$ Our results showed that DIOS significantly inhibited the proliferation of hepatoma cells and promoted G2/M cell cycle arrest, which was in close association with Chk signaling pathway. However, there have been few studies on signal pathways in which DIOS is involved, especially in the Chk signal transduction pathway. Therefore, we explored the relationship between Chk signaling pathway and cell cycle regulated by DIOS. The transition from $\mathrm{G} 1$ to $\mathrm{S}$ causes a cascade of cyclinD/CDK4 complexes to bind to CDK6, and the cyclinB/CDK1 complex will shift from G2 to $\mathrm{M}$ during mitosis. ${ }^{27}$ When DNA is damaged, the G2 phase-detection site will cause the cells to enter the mitosis phase for automatic repair. When cyclinB and cyclinA form a complex with CDK1, it is extremely important to generate an M-phase transition of the cascade activation pair. ${ }^{28}$ In our experiments, it was found that DIOS downregulated the protein expression of cyclinB/CDK1. There was no significant change in cyclinA expression after DIOS treatment. This indicates that DIOS may induce $\mathrm{G} 2 / \mathrm{M}$ phase arrest by down-regulating cyclinB/CDK1. In addition, with the accumulation of $\mathrm{p} 53$, dissociation from the MDM2 binding site, p53 gene promotes p21Cip1 accumulation, which is an inhibitor of $\mathrm{Cdc} 2 .^{29}$ This results in a decrease in the expression of cyclin $\mathrm{B} / \mathrm{cdc} 2$; therefore, the DIOS-induced cell cycle arrest in G2/M phase may be through the induction of the cyclinB1/cdc2 pathway. Our study showed that the expression of p53 and p21 increased in DIOS-treated human hepatoma cell line HepG2, indicating that DIOS-induced cell cycle arrest may also be related to the p53 signaling pathway. Meanwhile, DIOS down-regulated Bcl-2 expression through P53 and mitochondrial apoptosis pathway and up-regulated the expression of Bax, Bak, cleaved-caspase3, cleaved-caspase 8 and 
A

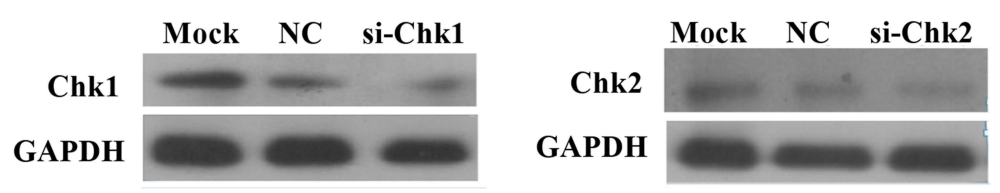

B

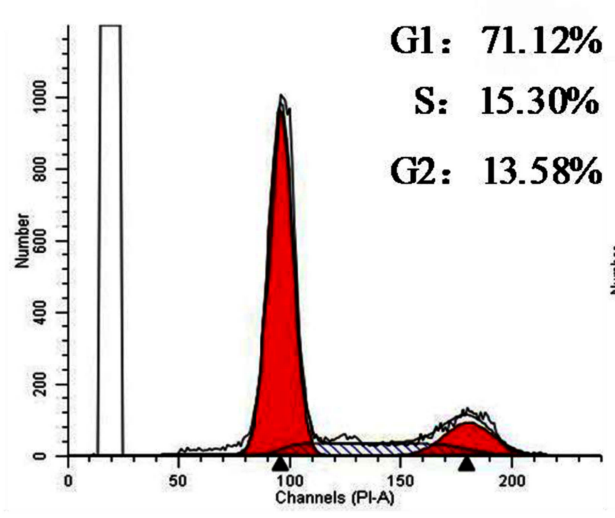

DMSO

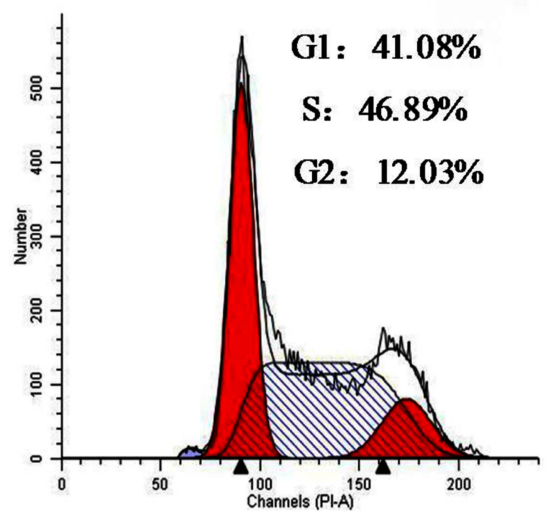

DIOS+si-Chk1
G1 : $28.84 \%$

S: $32.57 \%$

G2: $38.59 \%$

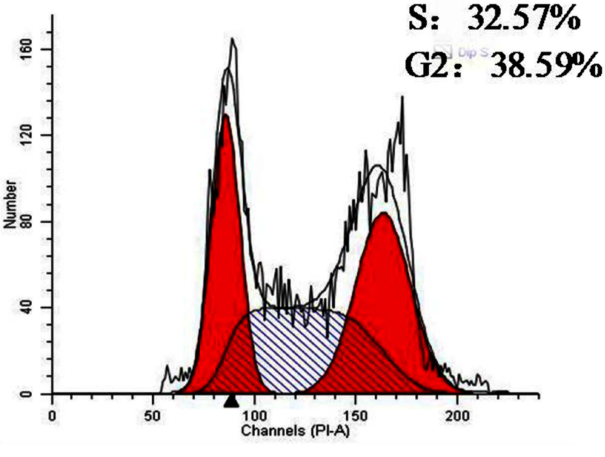

DIOS

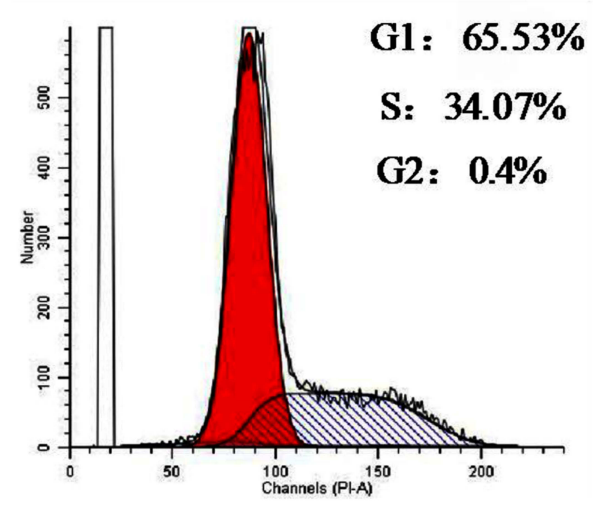

DIOS+si-Chk2

Figure 6 DIOS might promote G2/M arrest via Chk2 but not Chk1 in HepG2 cells. (A) Western blotting was used to detect the expression levels of cyclin ChkI and Chk2 in HepG2 cells transfected with Chkl-siRNA and Chk2-siRNA. (B) Flow cytometry was used to detect the cell cycle changes in HepG2 cells transfected with ChkI-siRNA and Chk2-siRNA.

Abbreviations: PI-A, propidium iodide-area; DMSO, dimethyl sulfoxide; DIOS, diosmetin; Chk2, checkpoint kinase 2; siChk2, small interfering RNA-checkpoint kinase 2; NC, negative control; ChkI, checkpoint kinase I; siChkI, small interfering RNA-checkpoint kinase I; GAPDH, glyceraldehyde-3-phosphate dehydrogenase; GI, postsynthetic gapl period; S, synthetic phase; G2, postsynthetic gap2 period; M, mitotic phase.

cleaved-PARP. Ultimately, DIOS promoted apoptosis and cell cycle arrest in G2/M phase through inducing the low expression of apoptosis-related proteins and cyclins.

DNA damage will result in the activation of ATM/ ATR, which induces Cdc25c phosphorylation to inhibit the activation of Chk1 and Chk2. ${ }^{30,31}$ Chk1 promotes phosphorylation by activating its ser317, ser345 and ser296 sites, and Chk2 activates its ser33/35, ser516, ser296, and Thr68 sites. ${ }^{32,33}$ Our study found that DIOS can induce high expression of p-Chk1 (ser317, ser345) and p-Chk2 (ser33/35). To elucidate the intrinsic mechanism of DIOS-induced cell cycle arrest, we detected the expression of Chk1 and Chk2 in HepG2 cells transfected with Chk1siRNA and Chk2-siRNA. We found that the change in G2 phase after Chk1-siRNA treatment was not obvious, but the proportion of G2 phase in HepG2 cells transfected with Chk2-siRNA was significantly decreased. This result demonstrated that the major signaling pathway regulating 
A

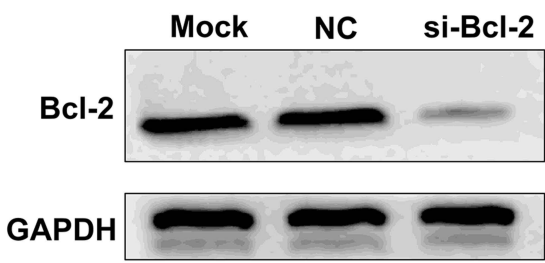

C

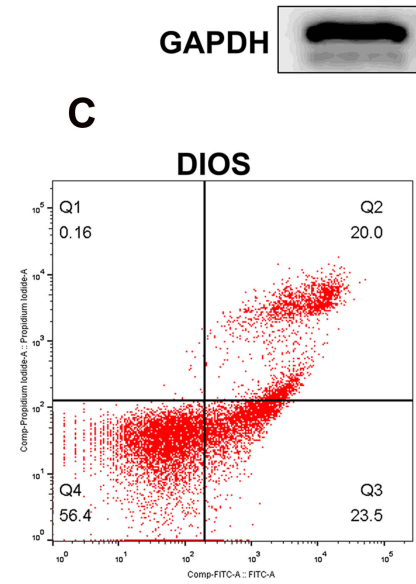

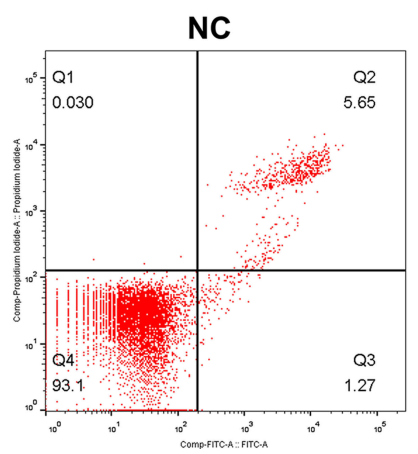
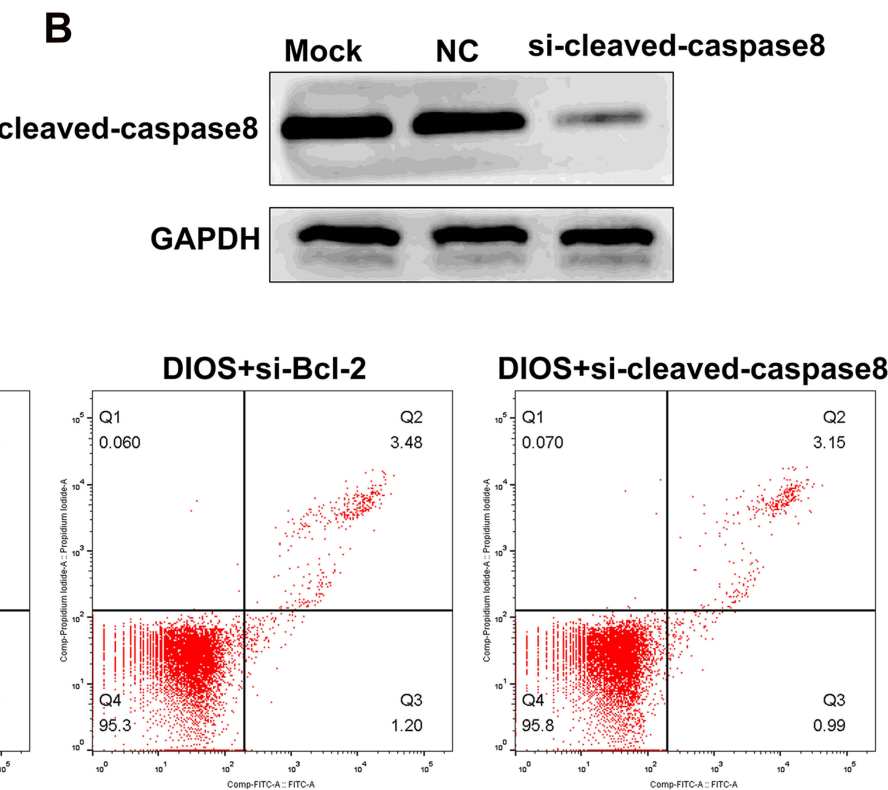

Figure 7 DIOS might promote HepG2 cell apoptosis by Bcl-2 and cleaved-caspase8. (A, B) The transfection effects of si-Bcl-2 and si-cleaved-caspase8 in HepG2 cells were detected using Western blot. (C) Flow cytometry was used to detect HepG2 cell apoptosis.

Abbreviations: NC, negative control; si-Bcl-2, small interfering RNA-B-cell lymphoma-2; Bcl-2, B-cell lymphoma-2; GAPDH, glyceraldehyde-3-phosphate dehydrogenase; si, small interfering RNA; FITC-A, fluorescein isothiocyanate-area; DIOS, diosmetin.

G2/M cell arrest could be the Chk2 pathway. The cyclinB/ CDK and p53 signaling pathways are not fully involved in the regulation of $\mathrm{G} 2 / \mathrm{M}$ cell arrest in HepG2 cells.

Taken together, our study showed that DIOS can cause proliferation inhibition, induce apoptosis and G2/M cell cycle arrest in human hepatoma HepG2 cells. Based on current research, DIOS may be a potential anti-tumor chemotherapeutic drug for liver cancer therapy. In future study, we will further clarify the role of DIOS in cell cycle arrest and signaling pathway in vitro and in vivo animal models, and provide new clinical treatment approaches for tumors.

\section{Conclusion}

In this study, our findings revealed that DIOS inhibited cell proliferation and promoted cell apoptosis in liver cancer cells. Furthermore, DIOS treatment induced G2/M cell cycle arrest in HepG2 cell by down-regulation of cell cycle-related protein cdc2, cyclinB1 and up-regulation of P53 and P21. Moreover, we also found that DIOS might promote HepG2 cell apoptosis by $\mathrm{Bcl}-2$ and cleavedcaspase8. Our research provides novel insights into the mechanism of DIOS against liver cancer.

\section{Abbreviations}

DIOS, diosmetin; Chk1, checkpoint kinase 1; siRNA, small-interfering RNA; Chk2, checkpoint kinase 2.

\section{Data Sharing Statement}

The datasets analyzed during the current study are available from the corresponding author on reasonable request.

\section{Author Contributions}

All authors made substantial contributions to conception and design, acquisition of data, analysis and interpretation of data, drafting the manuscript, revising the manuscript critically, read and approve the final draft of the manuscript for submission, gave final approval of the manuscript version to be published and agreed to be accountable for every step of the work.

\section{Disclosure}

The authors declare no conflicts of interest.

\section{References}

1. Greten TF, Lai CW, Li G, Staveley-O'Carroll KF. Targeted and Immune-based therapies for hepatocellular carcinoma. Gastroenterology. 2019;156(2):510-524. doi:10.1053/j.gastro.2018.09.051

2. Villanueva A. Hepatocellular Carcinoma. N Engl J Med. 2019;380 (15):1450-1462. doi:10.1056/NEJMra1713263

3. Yang YM, Kim SY, Seki E. Inflammation and liver cancer: molecular mechanisms and therapeutic targets. Semin Liver Dis. 2019;39 (01):26-42. doi:10.1055/s-0038-1676806

4. Bray F, Ferlay J, Soerjomataram I, Siegel RL, Torre LA, Jemal A. Global cancer statistics 2018: GLOBOCAN estimates of incidence and mortality worldwide for 36 cancers in 185 countries. CA Cancer J Clin. 2018;68(6):394-424. doi:10.3322/caac.21492 
5. Zheng R, Qu C, Zhang S, et al. Liver cancer incidence and mortality in China: temporal trends and projections to 2030. Chin J Cancer Res. 2018;30(6):571-579. doi:10.21147/j.issn.1000-9604.2018.06.01

6. Marengo A, Rosso C, Bugianesi E. Liver cancer: connections with obesity, fatty liver, and cirrhosis. Annu Rev Med. 2016;67 (1):103-117. doi:10.1146/annurev-med-090514-013832

7. Liu Z, Jiang Y, Yuan H, et al. The trends in incidence of primary liver cancer caused by specific etiologies: results from the global burden of disease study 2016 and implications for liver cancer prevention. J Hepatol. 2019;70(4):674-683. doi:10.1016/j.jhep.2018.12.001

8. Llovet JM, Montal R, Sia D, Finn RS. Molecular therapies and precision medicine for hepatocellular carcinoma. Nat Rev Clin Oncol. 2018;15(10):599-616. doi:10.1038/s41571-018-0073-4

9. Neureiter D, Stintzing S, Kiesslich T, Ocker M. Hepatocellular carcinoma: therapeutic advances in signaling, epigenetic and immune targets. World J Gastroenterol. 2019;25(25):3136-3150. doi:10.3748/ wjg.v25.i25.3136

10. Kudo M. Targeted and immune therapies for hepatocellular carcinoma: predictions for 2019 and beyond. World J Gastroenterol. 2019;25(7):789-807. doi:10.3748/wjg.v25.i7.789

11. Wang C, Jin H, Gao D, et al. Phospho-ERK is a biomarker of response to a synthetic lethal drug combination of sorafenib and MEK inhibition in liver cancer. J Hepatol. 2018;69(5):1057-1065. doi:10.1016/j.jhep.2018.07.004

12. Tsilimigras DI, Ntanasis-Stathopoulos I, Bagante F, et al. Clinical significance and prognostic relevance of KRAS, BRAF, PI3K and TP53 genetic mutation analysis for resectable and unresectable colorectal liver metastases: a systematic review of the current evidence. Surg Oncol. 2018;27(2):280-288. doi:10.1016/j.suronc.2018.05.012

13. Li Z, Zhang Y, Wang R, Zou K, Zou L. Genetic alterations in anaplastic thyroid carcinoma and targeted therapies. Exp Ther Med. 2019;18(4):2369-2377. doi:10.3892/etm.2019.7869

14. Cao X, Wang AH, Jiao RZ, et al. Surfactin induces apoptosis and G (2)/M arrest in human breast cancer MCF-7 cells through cell cycle factor regulation. Cell Biochem Biophys. 2009;55(3):163-171. doi: 10.1007/s12013-009-9065-4

15. Cerella C, Scherer C, Cristofanon S, et al. Cell cycle arrest in early mitosis and induction of caspase-dependent apoptosis in U937 cells by diallyltetrasulfide (A12S4). Apoptosis. 2009;14(5):641-654. doi:10.1007/s10495-009-0328-8

16. Dai QS, Liu W, Wang XB, et al. NCPMF-60 induces G2/M cell cycle arrest and apoptosis in human hepatocellular carcinoma HepG2 cells. Anticancer Drugs. 2011;22(1):46-57. doi:10.1097/CAD.0b013e3 283405801

17. Hu B, Shen KP, An HM, Wu Y, Du Q. Aqueous extract of curcuma aromatica induces apoptosis and G2/M arrest in human colon carcinoma LS-174-T cells independent of p53. Cancer Biother Radiopharm. 2011;26(1):97-104. doi:10.1089/cbr.2010.0853

18. Suh H, Choi KW, Lee CH. CR389, a benzoimidazolyl pyridinone analog, induces cell cycle arrest and apoptosis via p53 activation in human ovarian cancer PA-1 cells. J Microbiol Biotechnol. 2015;25 (3):418-422. doi:10.4014/jmb.1412.12080
19. Wu W, Ye H, Wan L, et al. Millepachine, a novel chalcone, induces G2/M arrest by inhibiting CDK1 activity and causing apoptosis via ROS-mitochondrial apoptotic pathway in human hepatocarcinoma cells in vitro and in vivo. Carcinogenesis. 2013;34(7):1636-1643. doi:10.1093/carcin/bgt087

20. Patel K, Gadewar M, Tahilyani V, Patel DK. A review on pharmacological and analytical aspects of diosmetin: a concise report. Chin J Integr Med. 2013;19(10):792-800. doi:10.1007/s11655-013-1595-3

21. Calderaro J, Couchy G, Imbeaud S, et al. Histological subtypes of hepatocellular carcinoma are related to gene mutations and molecular tumour classification. J Hepatol. 2017;67(4):727-738. doi:10.1016/j. jhep.2017.05.014

22. Li M, Lai X, Zhao Y, et al. Loss of NDRG2 in liver microenvironment inhibits cancer liver metastasis by regulating tumor associate macrophages polarization. Cell Death Dis. 2018;9(2):248. doi:10.1038/s41419-018-0284-8

23. Chen X, Wu Q, Chen Y, et al. Diosmetin induces apoptosis and enhances the chemotherapeutic efficacy of paclitaxel in non-small cell lung cancer cells via Nrf2 inhibition. Br J Pharmacol. 2019;176 (12):2079-2094. doi:10.1111/bph.14652

24. Choi J, Lee DH, Park SY, Seol JW. Diosmetin inhibits tumor development and block tumor angiogenesis in skin cancer. Biomed Pharmacother. 2019;117:109091. doi:10.1016/j.biopha.2019.109091

25. Oak C, Khalifa AO, Isali I, Bhaskaran N, Walker E, Shukla S. Diosmetin suppresses human prostate cancer cell proliferation through the induction of apoptosis and cell cycle arrest. Int J Oncol. 2018;53(2):835-843. doi:10.3892/ijo.2018.4407

26. Palmer N, Talib SZA, Kaldis P. Diverse roles for CDK-associated activity during spermatogenesis. FEBS Lett. 2019;593 (20):2925-2949

27. Hu X, Eastman AE, Guo S. Cell cycle dynamics in the reprogramming of cellular identity. FEBS Lett. 2019;593(20):2840-2852.

28. Hayward D, Alfonso-Perez T, Gruneberg U. Orchestration of the spindle assembly checkpoint by CDK1-cyclin B1. FEBS Lett. 2019;593(20):2889-2907. doi:10.1002/1873-3468.13591

29. Cmielova J, Rezacova M. p21Cip1/Waf1 protein and its function based on a subcellular localization [corrected]. J Cell Biochem. 2011;112(12):3502-3506. doi:10.1002/jcb.23296

30. Nilsson I, Hoffmann I. Cell cycle regulation by the Cde25 phosphatase family. Prog Cell Cycle Res. 2000;4:107-114.

31. Tao L, Cao Y, Wei Z, et al. Xanthatin triggers Chk1-mediated DNA damage response and destabilizes Cdc25C via lysosomal degradation in lung cancer cells. Toxicol Appl Pharmacol. 2017;337:85-94. doi:10.1016/j.taap.2017.10.015

32. Manic G, Obrist F, Sistigu A, Vitale I. Trial Watch: targeting ATM-CHK2 and ATR-CHK1 pathways for anticancer therapy. Mol Cell Oncol. 2015;2(4):e1012976. doi:10.1080/23723556.2015. 1012976

33. Ronco C, Martin AR, Demange L, Benhida R. ATM, ATR, CHK1, CHK2 and WEE1 inhibitors in cancer and cancer stem cells. Medchemcomm. 2017;8(2):295-319. doi:10.1039/C6MD00439C

\section{Publish your work in this journal}

Cancer Management and Research is an international, peer-reviewed open access journal focusing on cancer research and the optimal use of preventative and integrated treatment interventions to achieve improved outcomes, enhanced survival and quality of life for the cancer patient.
The manuscript management system is completely online and includes a very quick and fair peer-review system, which is all easy to use. Visit http://www.dovepress.com/testimonials.php to read real quotes from published authors. 